\title{
Supporting junior faculty in the academic system: time for a change?
}

\begin{abstract}
Recently, MIT professor and Nobel laureate Susumu Tonegawa has come under attack for allegedly opposing the recruitment of a female, prospective junior faculty member to MIT because her work would compete with that of his laboratory. While the accusations are still under internal investigation, this incident raises the important issue of how we scientists as a group succeed or fail as mentors for junior faculty.
\end{abstract}

Professor Tonegawa is accused of e-mailing a potential recruit and discouraging her from joining the MIT faculty because he was allegedly uncomfortable with the competition her lab would provide to his own research endeavors. Personally, I find it hard to believe that Professor Tonegawa, an outstanding scientist whose accomplishments are legendary, would be threatened by any junior faculty member. Moreover, Professor Tonegawa apparently made the personal choice to leave behind the Japanese academic system wherein senior, established faculty hold all the cards and often prevent junior faculty from establishing their own independent research programs. He has reportedly criticized the Japanese system in the past for not fostering the growth and individuality of younger scientists. Indeed, any system in which senior faculty can suppress the advancement of junior faculty threatens to hold back the best and brightest young scientists.

The timeline to tenure varies among institutions, and some provide up to ten years before a researcher's record of achievement is evaluated. At my own institution, Columbia University, members of the faculty are put forward for tenure after being given seven years to establish themselves. A somewhat backwards unwritten rule at Columbia is that junior faculty should avoid collaborating with senior faculty; otherwise, their chances for tenure can be reduced. This creates an unfortunate situation in which senior and junior faculty who could advance scientific understanding by collaborating are actually encouraged not to do so because it will harm the chances of the junior faculty member achieving tenure.

The academic system has a built-in perverse pressure for senior faculty to delay advancement of junior faculty who may compete with them for space and resourc- es. Yet all agree that the system cannot survive without continual infusion of new talent. Indeed, what happens when a scientist whose best days are past refuses to retire? Basic science departments can be burdened by such faculty, who contribute very little to the ongoing mission of the department yet continue to be paid sizeable salaries despite the fact they are producing little, have no grants, and are doing research that was cutting edge two or three decades ago.

I doubt that the tenure system was designed to protect nonproductive scientists; nevertheless, it does. It protects and preserves underperforming faculty, including those who are too proud to retire and move to emeritus status. Moreover, there needs to be a better system to honor those who have had important and productive careers and may still have a lot to offer but are no longer conducting productive, funded research programs. Corporations that have to answer to the bottom line do not tolerate this kind of abuse of the system, yet it is rampant in academia.

At many biomedical research institutions, faculty generally start out with the implicit understanding that we have to pay as we go - either you are productive and get grants or you are out. However, once faculty are tenured, many institutions take the path of least resistance and allow underproducing faculty to rob the system even though resources are scarce and the academic structure is being threatened by the need for accountability. Nevertheless, the tenure system is critically important to preserving academic freedom, as those who lived through the McCarthy era know all too well.

Currently, power is vested in senior, tenured faculty who not only establish the rules of conduct but also decide which junior associates can progress to the ranks of ten- ured professor. The ideal is that the senior faculty will make such judgments in the best interests of the university, but this may not always be the case. Universities need to be more flexible and creative in the ways in which senior and junior faculty are encouraged to work together for the advancement of science without impairing the career development of junior faculty. Clear statements of the contributions of junior faculty to collaborative scientific projects should be honored by tenure review committees. The alternative is a blanket prohibition against such collaborations, which is against the best interests of the researchers in promoting new advances.

Isn't it bad enough that the scientific system relies on the work of postdoctoral researchers who toil for long hours with little compensation, albeit establishing the groundwork for their future careers? Can't we come up with a better system? Such a system could be one in which there were adequate funds to pay postdoctoral researchers more comfortable wages and in which junior faculty were provided the opportunity to replace senior, established (read: tenured) faculty if their productivity and accomplishments merited such a move. Perhaps tenure should expire at some point toward the end of one's career, after which appointments could be extended on an annual basis or be modified (e.g., continued academic appointment but with reduced salary and space).

I believe these are concepts that need to be explored in order to maintain the vibrancy of the academic system. A balance has to be struck between showing proper respect for the accomplishments of established scientists and providing opportunities for junior faculty to advance and someday replace senior faculty. Universities need to acknowledge the value of senior faculty and respect their needs without hampering the active, productive faculty who must take over their spaces and positions in order for the system to have a healthy future.

\section{Andrew R. Marks, MD Editor in Chief}

